\title{
Patient Pathway Modelling Using Discrete Event Simulation to Improve the Management of COPD
}

Usame Yakutcan $^{\mathrm{a} *}$, Eren Demir ${ }^{\mathrm{a}}$, John R Hurst ${ }^{\mathrm{b}}$, Paul C Taylor ${ }^{\mathrm{a}}$

${ }^{a}$ Hertfordshire Business School, University of Hertfordshire, AL10 9AB, Hatfield, United

Kingdom; ${ }^{b} U C L$ Respiratory, University College London, Royal Free Campus, London, NW3

2QG, United Kingdom

*Correspondence: Usame Yakutcan, University of Hertfordshire, Hatfield, UK.

E-mail: u.yakutcan@herts.ac.uk 


\section{Patient Pathway Modelling Using Discrete Event Simulation to Improve the Management of COPD}

The number of people affected by chronic obstructive pulmonary disease (COPD) is increasing and the hospital readmission rate is remarkably high. Therefore, healthcare professionals and managers have financial and workforce-related pressures. A decision support toolkit (DST) for improving the management and efficiency of COPD care is needed to respond to the needs of patients now and in the future. In collaboration with the COPD team of a hospital and community service in London, we conceptualised the pathway for COPD patients and developed a discrete event simulation model (DES) incorporating the dynamics of patient readmissions. A DES model or operational model at this scale has never been previously developed, despite many studies using other modelling and simulation techniques in COPD. Our model is the first of its kind to include COPD readmissions as well as assessing the quantifiable impact of re-designing COPD services. We demonstrate the impact of post-exacerbation pulmonary rehabilitation (PEPR) policy and observe that PEPR would be cost-effective with improvements in quality-adjusted life years (QALYs), reduction in emergency readmissions and occupied bed days. The DST improves the understanding of the impact of scenarios (activities, resources, financial implications etc.) for key decision makers and supports commissioners in implementing the interventions.

Keywords: patient flow modelling; discrete event simulation; COPD; readmission, decision support toolkit

\section{Introduction}

Chronic Obstructive Pulmonary Disease (COPD) is a condition characterised by poorly reversible airflow obstruction that arises when a genetically susceptible individual is exposed to a sufficient environmental stimulus (usually cigarette smoke in high-income countries). About 3.2 million people in the UK are estimated to be living with COPD, but only 1 million are diagnosed and the disease causes an average of 30,000 deaths each year (Department of Health, 2011). 
COPD is one of the most costly chronic conditions (BLF, 2011) with the total direct cost to the NHS of the disease reaching $£ 1.85$ billion/year (Trueman et al., 2017), more than half being related to inpatient hospitalisation and emergency visits (Britton, 2003). The disease is the second most common cause of emergency admissions (13\%) after influenza and pneumonia (Tian et al., 2012). The UK has a higher rate of avoidable admissions (about 25\%) for asthma and COPD than the EU average (OECD/EU, 2016).

COPD exacerbation, defined as acute worsening of symptoms, is the main cause of unplanned emergency admissions. Exacerbation becomes more frequent and severe as the severity of COPD increases (Hurst et al., 2010). Emergency readmission within 30 days of discharge from hospital is one of the outcome indicators within the Public Health Outcomes Framework (Department of Health, 2015). The readmission rate (more than 15\%) is very high amongst COPD patients (Friebel et al., 2018). Also, the 30-day readmission rule, introduced in 2011/12, states that hospitals are either not, or only partly, reimbursed for emergency readmissions up to 30 days after discharge (NHS Improvement, 2016). Thus, nearly $£ 400$ million was withheld from English hospital budgets between 2011 and 2014 (Macnabb et al., 2014).

NHS Trusts are forced to make significant savings to deal with possible budget deficits of $£ 30$ billion by 2020 (Cooper, 2014). Thus, the alarming situation is that the NHS is faced with financial and workforce pressures due to increasing demand and lack of financial resources challenging the delivery of effective care.

While there are many modelling studies about cost-effectiveness of new drugs, therapies and treatments for COPD, the quantifiable impact of re-designing COPD services has never been previously studied. There are no known models that capture individual patient pathways within COPD services with the aim of investigating the impact of changes in policies or the introduction of new policies in terms of re-designing COPD services, workforce planning, and 
dealing with patient readmissions. Furthermore, a new approach is urgently needed in order to enhance the efficiency and quality of patient care as well as reducing the costs of COPD management by making reasonable suggestions for key decision makers.

This is challenging because patients with COPD are cared for across primary services (PC), community services (CS) and secondary care services at different points in their disease trajectory. Whether planned changes will actually result in increased capacity, improve patient outcomes, and/or lead to savings, and if so by how much is yet to be established. Furthermore, how a change in one area of the service will impact on resources in another including activity (new and follow-up (FU) appointments, emergency admissions), resource utilisation, costing and revenue is unknown.

Therefore, the core objectives of this study are as follows:

(1) To develop a discrete event simulation (DES) model that captures COPD treatment pathways and service configurations within a hospital setting. Simulating the patient pathway involves the representation of patients' journeys, allowing for the influence of factors such as age, gender, disease severity, length of stay, and diagnosis. For the first time, this model will enable users to evaluate the impact of the implementation of service re-design on a number of operational and cost performance indicators relevant to the delivery of COPD services.

(2) To develop an innovative approach combining DES with the concept of patient readmissions. A model differentiating initial admissions from readmissions and carrying information from previous admissions, such as length of stay in the community, age, and disease severity is an absolute necessity. To our knowledge, the literature does not have any study that integrates COPD readmissions within a single modelling framework. 
(3) To develop a user-friendly simulation model of COPD patient pathways to enable hospital managers and practitioners to test a wide range of scenarios and policy changes (e.g. strategies to prevent patient readmissions) to improve the management of the disease, and determine possible and realistic policies that can be implemented in practice.

The remaining sections of the paper are organised as follows: literature review (section 2), materials and methods (section 3), results (section 4), and discussion (section 5).

\section{Literature Review}

Healthcare simulation studies in the literature have been reviewed several times by different researchers. Firstly, Fone et al. (2003) reviewed 182 papers systematically from 1980 to 1999 under the following headings: scheduling and organization of hospital; contagious disease and infections; costs and economic evaluation; screening for disease; and lastly miscellaneous. Additionally, Gunal and Pidd (2010) classified studies according to the application areas for performance modelling. Recently, Karnon and Afzali (2014) reviewed DES papers which assess health technologies in terms of economy (articles published between 2000 and 2013). Lastly, Brailsford (2007) proposed a three-level classification: the human body models (disease models); the operational models of healthcare units; and strategic whole-system models. As our study is about modelling the COPD patient pathway, studies for COPD models or simulations as well as DES models for disease pathway are reviewed.

\subsection{COPD Models and Simulation}

In the literature, many studies have been carried out so far on COPD, where the majority focused on the cost-effectiveness of COPD treatments and drugs as well as transition and the 
burden of the disease, by using Markov modelling (MM), Monte-Carlo simulation (MCS), agent-based simulation (ABS), system dynamics (SD), and recently DES.

Disease progression and future prevalence of COPD were investigated by using various techniques, such as ABS, MM, mathematical modelling (Charfeddine and Montreuil, 2010; Hoogendoorn et al., 2011; Tan et al., 2015). Also, MM and MCS have been used for costeffectiveness analysis of interventions and drugs by using QALY (quality-adjusted life year) and cost per QALY gained as performance outcomes (Asukai et al., 2013; Atsou et al., 2011; Atsou et al., 2016; Borg et al., 2004; Menn et al., 2012; Nielsen, 2009; Oostenbrink et al., 2005; Sin et al., 2004; Spencer et al., 2005).

Surprisingly, there appears to be no modelling study for COPD at an operational level. Only recently two groups of researchers have applied DES to COPD and neither are at an operational level (Hoogendoorn et al., 2019; Sadatsafavi et al., 2019). A patient-level DES model assessed cost-effectiveness by capturing disease progression typically seen in MM, rather than a hospital setting level (Hoogendoorn et al., 2019). Hypothetical scenarios, such as simulating 20\% reduction in annual decline in lung function or $30 \%$ increase in time to an exacerbation, are tested instead of specific change in treatment or drug. Moreover, a DES model used an opensource approach to enable users to project the outcomes of the disease in Canada (Sadatsafavi et al., 2019). Although the population-based model incorporates the natural course of the disease (decline in lung function, probability of exacerbation, mortality etc.) and patient characteristics, it does not include the operational aspects (clinics, treatment, hospitalisation etc.) and does not evaluate any scenario for improving the care. Capturing operational aspects is important because it enables key decision makers to see the impact of changes (for efficiency improvement) in the patient pathway on performances and resource usage. 
In the DES studies for evaluating the cost-effectiveness of drugs or therapies for smoking cessation, COPD has only considered as an outcome of smoking (Getsios et al., 2013; Igarashi et al., 2016; Mayorga et al., 2014; Xenakis et al., 2011). Lastly, a population model using SD assessed the financial impact of hypothetical scenarios (e.g. screening test, slowing the progression into more severe disease stages, and predicting exacerbations) for COPD patients in Canada (Najafzadeh et al., 2012). Najafzadeh et al. (2012) also point out the need for an investigation for a change in exacerbations (hospitalisations) on morbidity and cost.

\subsection{Disease models using DES}

DES is a useful method to model the course of diseases, which enables users to track patients individually and capture the organisational issues in the healthcare setting (e.g. clinic, resources, waiting times). In the healthcare context, DES is generally used to help decision makers improve the efficiency of their setting. Therefore, the general use of DES can be categorised as follows: (i) conceptualisation of disease pathways to compare for alternative intervention comparisons (disease progression modelling); (ii) increasing the understanding about the working and relationship mechanism of the system (health and care systems operation); (iii) projecting the impact of earlier detection of the diseases (screening modelling); and (iv) finding the most effective intervention considering the individuals` changeable behaviours (health behaviour modelling) (Zhang, 2018).

In the literature, DES has been applied to various diseases for different objectives, such as to assess the health impact or cost-effectiveness of new treatments, drugs or screening policy, or to represent the spread of contagious diseases as well as to model patient pathways. For example, the impact of alternative interventions on health and economic values are tested for cardiac conditions, deep vein thrombosis, Alzheimer's disease, diabetes, stroke, and osteoarthritis (Caro et al., 2006; Demir and Southern, 2017; Getsios et al., 2012; Harper et al., 
2003; Mar et al., 2010; Ward et al., 2007). Communicable diseases, such as malaria, HIV, or chlamydia have also been modelled to assess the ability of new interventions to prevent the contraction or the spread of disease using DES (McKenzie et al., 1998; Simpson et al., 2012; Rauner et al., 2005; Viana et al., 2014; Vieira et al., 2003).

Use of DES in the evaluation of screening policy became popular in the 2000s and studies have been carried out for diabetes, hip dysplasia, breast cancer, and cardiovascular disease (Brailsford and Schmidt, 2003; Brailsford et al., 2007; Comas et al., 2014; Crossan et al., 2017; Davies et al., 2002; Ramwadhdoebe et al., 2009). Lastly, DES has also been used for developing decision support tools, designing patient pathways, or capturing disease progression for stroke, coronary heart disease, cataract, depression, Parkinson's disease, and prostate cancer (Chemweno et al., 2014; Cooper et al., 2002; Demir et al. , 2018; Le Lay et al., 2006; Lebcir et al., 2017, Pan et al., 2018).

\section{Materials and methods}

The steps followed in this study include the selection of modelling type, conceptualisation of the COPD pathway, data collection and analysis. These steps are explained in detail below.

\subsection{Selection of Simulation Technique}

Statistical approaches, SD modelling, DES, and ABS are commonly used simulation techniques in healthcare management studies. The statistically driven models like MCS, MM and mathematical models make use of random variables or inputs based on probability distributions. Events happen or states change according to probabilities. SD modelling focuses on flows of cohorts and groups and has a cause-effect relationship. SD is a high and strategic level approach, where the interest lies in the dynamic complexity of a system. ABS is used for modelling complex and/or adaptive systems and shows the actions and interactions of agents. 
ABS captures autonomous behaviour, heterogeneity, adaptive behaviour, social network structures and geographical representation. On the other hand, DES is defined as the modelling of systems where the state variable changes only at a discrete set of points in time (Banks et al., 2005). DES makes use of entities and any type of features such as age, gender, or disease states can be assigned accordingly.

On a related note, Le Lay et al. (2006) and Simpson et al. (2012) compared MM and DES by modelling the diseases of depression and HIV/AIDS, respectively. Le Lay et al. (2006) stated that DES is more flexible in terms of the understanding of uncertainty in a system, being better at modelling complex systems and evaluating scenarios. Moreover, Simpson et al. (2012) noted that DES represented the course of a disease more naturally and predicted model outcomes in detail. However, due to its simplicity, MM and MCS are preferred by researchers who have no background in simulation and programming. In addition, Brailsford (2007) describes that DES focusses on the trees in a picture, whereas SD allows seeing the big picture but not as much detail as DES. SD is not appropriate for patient or entity focussed studies. ABS is best used when the behaviours of agents and interactions between them are complex and when populations and interactions are heterogeneous (Bonabeau, 2002).

Gunal (2012) states that the attractive features of DES for modellers are: flexibility; modelling of individual entities (patients); probabilistic distribution of data input; tracking queues and adjusting their priorities; and animation. Furthermore, Chahal and Eldabi (2008) mentioned that in the event of patient pathway renovation (i.e. a change in the pathway, new policy or intervention), alternative scenarios can be evaluated via DES. In the review by Karnon and Afzali (2014), the positive aspects of DES are listed as: (i) allowing the model to reflect the heterogeneity in a population; (ii) the ability to change event rates according to time; (iii) continuous disease progression; and (iv) influence of prior events on subsequent event rates. 
Furthermore, DES is recommended as an appropriate method for projects concerning visualisation or redesigning clinical pathways, whole hospital simulation, and testing interventions for efficiency improvement by NICE (National Institute for Health and Care Excellence) Guidelines Technical Support Unit (Pitt et al., 2013). DES is also well understood and accepted by NHS management, consultants, nurses, service managers and NICE. Therefore, DES is chosen as the simulation tool for this study, because it is more capable and convenient to model the hospital environment in which processes and events happen at discrete times. As our model is entity (patient) based, we can evaluate a wide range of what-if scenarios in the safety of a simulation environment. Lastly, this study is operational level modelling and DES is a widely used technique for this purpose.

\subsection{Conceptualisation of COPD Patient Pathway}

Conceptualisation enables developers or researchers to build a simulation model as well as to understand and see the movement of patients more clearly. Mapping the patient pathway is very useful to detect inefficiencies, suggest improvements for patient experience and reduce cost.

Therefore, an initial COPD patient pathway was established based on the interactive flowchart of NICE (2016a) for COPD diagnosis and assessment. This flowchart is basic and more appropriate for practical use (rather than for modelling purposes), but it provided a starting point. In the current study, in-depth interviews with COPD healthcare professionals were conducted to better understand the operational process of the COPD pathway. The study has been carried out with input from a COPD team consisting of specialist consultants, nurses, physiotherapists, and a service manager from Royal Free London NHS Foundation Trust, as well as the local community COPD services, run by Central and North West London NHS Foundation Trust. 
The initial pathway was revised and finalised after meetings and discussions with the COPD team between March and June 2017. After the round table meetings, the pathway became highly detailed and captured the most important steps in COPD treatment. Gunal (2012) states that complexity reduces the understanding of a model as well as the practical usage of the simulation tool by key decision makers (i.e. those responsible for the management of a hospital unit or patients). Therefore, the pathway was adjusted and fine-tuned according to experts' opinions by considering important areas of development. Data availability, reflecting the problems and the nature of the disease are also key issues to consider. Lastly, the pathway was verified and the scenarios (or impact of change) to be tested in the model were determined with the team at Royal Free Hospital (RFH) along with suggestions from the literature.

The patient pathway (see Figure 1) shows the possible movement of patients, referral/discharge points and departments, clinics, and services that are usually visited by COPD patients within a hospital setting. As the study is an operational level simulation model, elaborating the pathways is needed to capture and reflect the reality and the movement of patients. According to the interviews conducted, typical COPD care in England involves diagnostic, treatment, outpatient services, follow-up (status check), emergency intervention activities and elective and non-elective admissions.

3.2.1 Outpatient Department Pathway: Typically, patients are referred to a COPD outpatient clinic by GPs (General Practitioners), CS or other hospital departments and wards. There are four COPD clinics at the Royal Free, namely COPD, Non-Invasive Ventilation (NIV), Alpha1, and Advanced. Patients may also be seen in general respiratory clinics, and three additional outpatient services, namely physiotherapy, pulmonary rehabilitation (PR), and lung function testing. 
The clinics, which also require different types and numbers of healthcare professionals, run on specific days, time, and in different frequency, e.g. Alpha-1 clinic once a month on Thursdays and COPD clinics every Monday. Moreover, the waiting times for outpatient services vary between 4 and 8 weeks.

After visiting reception and being observed by health care assistants, patients are seen by physicians. Patients with any type of respiratory disease are treated in these clinics, not just those with COPD. After the clinic assessment, patients are either discharged (to PC or CS) or given a follow-up appointment (usually for a time after 6 months after clinic assessment). Patients can also be referred by consultants to outpatient services, such as PR and physiotherapy, depending on their needs (even if they are discharged). Patients who do not attend their appointments are discharged unless their disease has a specific requirement for follow-up.

3.2.2. Disease Severity Transition Pathway: The pathway also includes the course of the disease assessed by spirometric disease severity levels, namely GOLD 1 (Mild), GOLD 2 (Moderate), GOLD 3 (Severe), and GOLD 4 (Very Severe), which are based on the GOLD classification (GOLD, 2018). Disease transition happens one step forward, e.g. from mild to moderate or severe to very severe. Death can occur at any type of severity and it can be related to COPD or other causes.

3.2.3 Accident and Emergency (A\&E) Department Pathway: According to our analyses of the national data, the vast majority of COPD related inpatient admissions occur as non-elective (96\%) stays, mainly via A\&E (77\%). Nearly all inpatient admissions from A\&E are related to COPD acute exacerbation. After the initial assessment, COPD patients are referred to the medical team in medical assessment unit (MAU) to be admitted to hospital (i.e. inpatient care) when necessary. 
3.2.4 Inpatient Department Pathway: Patients come into inpatient departments in two ways, either as a non-elective admission (A\&E or other), or, very rarely, elective. Patients are bedded in the MAU, then a respiratory or Care of the Elderly $(\mathrm{CoE})$ ward (if the patient is older than 80 years). A consultant is responsible for medical care while patients are in the inpatient ward. A registered nurse is assigned to each patient to deliver and monitor medical care and deliver nursing care by routine visits. Patients who need more intense or specific care may be transferred to the Intensive Care Unit (ICU).

Patients might move back and forth between units/wards within the inpatient department. Patients move out of the inpatient department to either discharge to PC or discharge to CS or death. After discharge and spending time in the community, some patients may be readmitted to $A \& E$ and subsequently transferred back to inpatient department. Patients could be readmitted or have multiple admissions after spending time in the community. Note that readmission within 30 days and readmission within 90 days are used as performance indicators by the NHS.

\subsection{Information and Data Sources for the Model}

Data sources in the study are archival records, interviews, national healthcare datasets and relevant COPD studies in the literature. COPD data were obtained from the Hospital Episodes Statistics (HES) dataset which contains detailed records of all patients admitted to care providers in England. Other modelling requirements (patient pathway and input parameters, such as a mix of resources, number of visits, referral to services etc.) were obtained through semi-structured interviews, questionnaire, and group meetings with the COPD team at RFH. The literature was consulted for additional data, such as disease severity transitions (Atsou et al., 2011), attendance rate for PR (NACAP, 2017) and cost of treatments (Department of Health, 2013). 
HES is a database containing details of all admissions, A\&E attendances and outpatient appointments at NHS hospitals in England (data size greater than 250 gigabytes). The dataset has more than 250 columns of data with distinct variables across the three services (A\&E, inpatient and outpatient departments). As a result, database programming is needed to upload the dataset to a suitable database management system, open data files, derive variables of interest and match the patient records in each separate data file. HES data were cleaned and exhaustively analysed using Microsoft SQL Server. Encrypted patient number, age, gender, type of admission, diagnosis code, length of stay, date of admission, waiting times, treatment times, and referral source are some of the variables of interest.

The data period was from $1^{\text {st }}$ April 2010 to $31^{\text {st }}$ January 2013 equivalent to 2.84 years. Firstly, COPD related inpatient admissions (ICD-10 codes J40-J44) at RFH in the first diagnosis column (diag_01) were extracted. Duplicate, incomplete, and inaccurate records were removed (around 8\%) using HES ID number, date of admission, date of discharge, and primary diagnosis.

During a hospital stay a patient might encounter several successive episodes, collectively known as a spell. For example, a patient could be seen by multiple consultants, each for a different purpose, resulting in successive episodes. To determine the exact demand in admitted patient care (Inpatient), the data were reduced to spell level by removing consecutive episodes. In total, 2,005 episodes were extracted which were made up of corresponding to 1,037 spells/visits/admissions during the study period. Referrals to critical care in the inpatient department are recorded at the episode level. Patients in critical care are retrieved by matching "susrecid" code (secondary uses service generated record identifier) with admitted care data. In addition, $A \& E$ visits related to $C O P D$ which ended with referral to the inpatient department were captured by matching the A\&E and inpatient datasets (using unique HESID) in Microsoft SQL. 
Outpatient HES data gives information at the speciality level in which it is impossible to differentiate reasons for attendances, i.e., attendances could be related to any type of respiratory or other specialities. Also, the speciality of the attendances is too broad, such as general medicine and respiratory medicine, even if COPD related. Moreover, it does not provide information about disease severity, referral to outpatient services, or clinic type. Therefore, relevant local data and information from the hospital were used to develop a more realistic model. Outpatient activity data were acquired from the hospital with the help of the COPD team at RFH through regular meetings and by using expert opinion (e.g. from respiratory medicine consultants).

\subsection{Input Parameters}

A remarkable number of input parameters are needed to power the model, as the model simulates all related departments in the hospital along with the disease progression. Inputs for the model include demand, pathway-related parameters (mix of resources, treatment times, number of follow-ups, etc.), treatment costs and revenues. The parameter values are calculated using the following data sources, the HES dataset, the literature, national documents, local data and local experts (the COPD team at RFH).

More than 100 distributions (i.e. theoretical or frequency distributions) are established using the data (mostly HES dataset). Theoretical distributions are fitted using EasyFit (Mathwave, 2017), and frequency distributions (FD) are established using Microsoft Excel. The data used are presented in Table S1 in Appendix 1, where the data collection type, distribution type, and the input data for experimentation are all explained. The end-users of the model, such as service providers, can change all input parameters according to their hospital settings, patient demographics and geographical area. 
As the full list of the input parameters is too long, a selected sub-set of the input parameters with details are given in Table 1 for ease of understanding. For example, time related distributions are formed using HES dataset for A\&E department (e.g. Pearson VI for treatment time) and for inpatient department (e.g. Gamma for waiting time for elective appointment, FD for length of stay (LoS) in the hospital). On the other hand, most distributions related to outpatient department and outpatient services (e.g. Uniform for treatment times, Bernoulli for attendance rates) are formed using local data or local experts (i.e. COPD team).

Moreover, most distributions are specified separately for different groups (based on clinic type, primary diagnosis, and admission type). For instance, probability of being given a FU appointment (Bernoulli) by clinic type, daily demand in Inpatient type $(F D)$ by admission, and length of stay for elective admissions $(F D)$ by primary diagnosis (J40-J44). This stratified approach enabled us to obtain more reliable outputs and depicts reality.

Lastly, resource inputs (e.g. staff and rooms) and capacity information, were provided by the team at RFH, which are fixed values. Cost, revenue, administration aspect of PR (attendance, enrolment, completion rates) and disease severity transition probability were some of the inputs obtained from the literature and national documents (e.g. National Tariffs Workbooks published by NHS Improvement, 2018).

\section{Results}

\subsection{Simulation Model}

The details of the simulation settings and control logics are presented in this section (see Figure 2). More than 1,000 lines of codes were written to model the pathway using Simul8 (a simulation software) for various purposes. As an example, decision rules (discharge, followup, referral, readmission, etc.) were based on labels/variables, individual patients were tracked, 
and disease severity of patients was updated during simulation run. Also, results for each run and statistical measures (e.g. mean, standard deviation and confidence intervals) were collected and calculated via the coding. The model was run for a simulation period of 3.5 years to capture individual patient's trajectories and measure key performance indicators.

The annual increase in new patients with COPD in the Outpatient department was specified via HES data (in this context a $5.4 \%$ increase is projected). Time is a key component in a DES model. Therefore, the model reflected the operating times of an Outpatient department and services (Monday to Friday 9 am to $5 \mathrm{pm}$ ) and A\&E and inpatient departments (24/7). The model also represented the key constraints of a hospital setting, e.g. waiting times, resource capacity constraints (staff, clinic room, bed), and movement between departments.

The outpatient part of the model captured the features of the clinics and outpatient services, i.e. day and frequency of clinic/service, type and number of resources. As distinct from other treatments, the PR programme includes 16 sessions taking place twice a week for 8-weeks, where patients are assessed before and after the programme is completed. In addition to attendance rates for clinics and services, completion rate was considered in the model for the PR programme, as there are multiple sessions to attend.

When entities (patients) are generated in the model, they are assigned various labels; probability of attendance, gender, age group, disease severity, clinic type, etc. Patients move through the pathway depending on the probability rates or waiting times which are all assigned based on their labels. In parallel, a duplicate of the entity (patient) is generated in the disease severity progression part of the model (see the top left of Figure 2). The duplicate, which carries the same labels (gender, disease severity, age group etc.) about the patient, is sent to the relevant disease severity module (i.e. mild, moderate, severe, very severe). 
The model considered the deterioration of disease severity for patients over time. This aspect of the pathway was modelled using a probability matrix of transition from one stage of severity to another or to death. Probability ratios were derived from Atsou et al (2011) by considering the demographic values of the hospital (see Table 2), i.e. age and smoking status of COPD patients. Cycle time was assumed as 1 year based on Atsou et al. (2011). Note that death can occur at any stage of disease severity.

When deterioration happens, the patient's disease severity label is updated accordingly. Also, patients who die are removed from the model. The disease severity progression mechanism enabled us to send patients to the right clinic and collect the cost by disease severity. Also, the impact of interventions around slowing down the disease severity progression can be assessed by the users.

In A\&E and inpatient services part of the model, the labels (gender, age group, and primary diagnosis) were assigned by admission type (non-elective via A\&E, other non-elective, and elective). Elective patients enter the hospital after waiting for the appointment according to the distribution derived from the data. HES data contains information on patients' illnesses/conditions using defined ICD-10 codes (https://www.who.int/classifications/icd/icdonlineversions/en/). Primary diagnosis gives an indication of the reason for admission and of the disease type, where COPD has five main diagnosis categories (i.e. J40, J41, J42, J43 and J44). Therefore, on arrival to inpatient service, COPD patients were assigned an ICD-10 code (according to the frequency distribution established using HES data).

In the inpatient part of the model, the statistical distributions and input parameters varied depending on the patient's diagnosis category. Healthcare Resource Group (HRG) classification is a way of grouping clinically alike episodes/treatments which are regarded as 
consuming a similar level of resource and this is used to determine the revenue of hospitals in England (Department of Health, 2012). Therefore, the distributions (e.g. LoS in the hospital, risk of readmission, LoS in the community, HRG code, and referral to critical care) were assigned to each patient depending on their diagnosis category. This differentiation allows model users to reflect reality and test the scenarios for a specific type of patients.

The model also included a comprehensive costing and revenue calculation, which considers penalty due to readmissions, short-long stays, and multiplier effects. The total tariff of inpatient admissions was adjusted by adding long stay payment (for the number of days exceeding the trim point (days) for the HRG code as set in the National Tariff) or making reduction in the tariff due to short stay where applicable. Moreover, the possible cut on reimbursement (the penalty) due to 30-day emergency readmissions was calculated by multiplying the total revenue of the related admissions with the ratio determined in Sg2 (2011) guidance. Lastly, the revenue of the hospital was multiplied with the market forces factor (MFF) of the hospital due to operating cost differences based on location. The patient readmission dynamic of the model, which is a novel approach in operational modelling, is explained in detail in the next section.

\subsection{Patient Readmissions}

Patients can be admitted to hospital on multiple occasions over a period of time, either for the same condition or other reasons. At Royal Free Hospital, there were 963 emergency inpatient admissions from 563 patients during the data period (i.e. 1.7 admissions per patient). According to the national HES dataset, $63 \%$ of all COPD emergency inpatient admissions in England are caused by $33 \%$ of COPD patients. The figures for RFH are in line with the national figures, i.e., $59 \%$ of admissions are from $29 \%$ of patients. 
There are patient level A\&E and inpatient department simulation models in the literature (none for COPD) however, patient readmissions have never been considered within a modelling framework. In these studies, patients who are discharged from the hospital are discarded from the system by not allowing another admission (see top left of Figure 3). Consequently, admissions are not differentiated if it is an initial admission or a readmission (bottom left of Figure 3). Also, the admission does not have any information from previous admissions, such as length of stay in the community, age, disease stage etc.

Therefore, we developed a dynamic simulation model where the concept of readmission is embedded. Thus, the user is able to investigate the effectiveness of a series of interventions aimed at reducing emergency readmissions. This novel framework enables patients to be readmitted (after spending time in the community, i.e. LoS in the community) to the inpatient department via A\&E. LoS in the community is the time between discharge from a previous admission to next inpatient admission via A\&E.

Firstly, patients who are readmitted back to hospital after discharge are extracted through an intensive analysis of HES data. The likelihood of readmission is embedded into our simulation by establishing the frequency distribution of LoS in the community (i.e. the time spent in the community before a patient is readmitted). Note that the distributions for the risk of readmission and LoS in the community are stratified for each diagnosis label (i.e. reason for admission, J40-44). Therefore, the simulation model assigns the likelihood of readmission to each patient right after discharge from inpatient services (see the right-hand side of Figure 3).

This approach enables us to track an individual patient's journey from discharge to the next admission. More importantly, patients having a readmission within 30 days or 90 days are labelled, so that we record their admissions accordingly, as patient readmissions are an important performance indicator in the NHS. This will then enable us to apply a tailored 
intervention in this group of patients. Thus, hospital managers and practitioners are able to examine the impact of scenarios related to preventing readmissions.

\subsection{Model Validation and Verification}

The pathway and model are verified via meetings with COPD specialist clinicians. The structure of the conceptualised pathway was confirmed to be highly representative of the realworld COPD system. The model was validated by comparing the known data in the actual care system with the simulation results. The following parameters are chosen for comparative purposes: follow-up to new patient ratio for the outpatient department; average time spent in $\mathrm{A} \& \mathrm{E}$ for the $A \& E$ department; 30-day readmission rate the inpatient department. The difference between real-life data and the simulation model is calculated as within $5 \%$ either side of the expected result (within the range of the $95 \%$ confidence interval) indicating that the model can be used for further experimentation and usage (See Table 3).

Also, the required minimum replication number for the model is determined using FixedSample-Size procedure (Law and Kelton, 2000). The analysis is carried out for the selected key performance metrics for the hospital departments, i.e. total number of appointments in the clinics and the average time spent in A\&E. The values of the parameters of the Fixed-SampleSize procedure along with the calculation results are presented in Table 4 . As a result, minimum 10 replications are accepted as the replication number because the relative error of the run $\left(n^{*}(\mathrm{Y})\right)$ is found to be less than (or equal) to the value of adjusted relative error $\left(\mathrm{V}^{\prime}\right)$.

Most parts of the model (A\&E, outpatient and inpatient departments) reach a steady state in a short time (within weeks), whereas outpatient services take longer (i.e. months) than other settings (e.g. clinics, wards). This is due to patients been referred to outpatient services (e.g. 
PR) through clinic visits, where waiting times can vary from 4 to 8 weeks after referral. The warm-up period is calculated for the number of patients assessed for PR via Welch's method to prevent an initialisation bias (Robinson, 2004). The warm-up period is determined as 6 months, and the result can be seen in Figure 4.

\subsection{Experimentation}

The possible impact of post exacerbation pulmonary rehabilitation (PEPR) policy was assessed as the experiment. PEPR is a new intervention (NICE, 2016b) where patients are referred to PR (an exercise and education programme) within a short time after discharge (7-15 days) from hospital following an acute exacerbation. The intervention has a real potential of improving patient outcomes, such as exercise capacity, quality of life and disease symptoms, in addition to reducing the risk of hospital readmission (Lewko et al., 2015; Man et al., 2004; NICE, 2016b; Puhan et al., 2016).

The intervention could decrease the pressure on hospitals and staff and provide significant savings to the NHS as a result of reduction in hospitalisation, and the number of visits to COPD services. More importantly, the increase in the quality of life (Atsou et al., 2016), exercise capacity and prevention of problems (such as anxiety and depression) caused by hospitalisation (Hollmann et al., 2013) are added benefits to patients.

However, PEPR programmes have not been widely implemented. Based on a search of the literature, PEPR has never been investigated to understand the impact of this intervention on key metrics, such as activity, resources, financial implications, and patient readmissions. Roll out of such services would require investment and thus modelling its impact will be informative. 
Therefore, we tested for a range of potential impacts that PEPR policy may have on key performance metrics. The duration of PEPR and its impact on patient outcome varies a lot. For instance, the reduction in readmission rates could be as low as $0 \%$ (Greening et al. 2014; Roberts et al. 2013) and as high as 50\% (Lewko et al., 2015; Seymour et al., 2010). Therefore, four sets of scenarios (worst, pessimistic, realistic and optimistic scenarios, see Table 5) were established for the indicators of interest. The parameter values (i.e. reduction in readmission, decrease in LoS, follow-up duration, and effective period of PEPR) for each of the scenarios were based on previous studies and expert opinions. For example, Eaton et al. (2009) found a $25 \%$ reduction in readmission after PEPR policy (pessimistic scenario), whereas Behnke et al. (2010) no effect (worst scenario). The justification and levelling of the scenarios as well as the parameters are explained in detail in Appendix 2.

The new intervention and its impact were incorporated with the model. Prior to discharge from inpatient services, our model assigns the risk of readmission for each patient by their reason for admission (i.e. J40-J44). The positive effect of PEPR is applicable for a group of patients. The intervention will not be effective for patients whose LoS in the community is less than 15 days, because they can only start the PR programme after a period of time. In summary, patients (e.g. those who completed the PEPR) are randomly prevented from re-admission in the model by using a reduction rate coming from the experiment. The model also takes into account the eligibility rate for referral and the completion rate for the programme.

\subsection{Scenario Outputs}

The model was run 10 times using different seeds for a period of 3.5 years (with a warm-up period of 0.5 year), where means and $95 \%$ confidence intervals are estimated accordingly. The results exclusively show that the use of PEPR decreases inpatient admissions, emergency 
readmission, occupied bed days and the loss of QALY utility. The key outputs are presented and briefly explained below with a cost-effectiveness analysis.

PR Programme Results: According to the simulation results, referrals to PR dramatically increased by more than $113 \%$ and the number of patients completing the PR programme raised by $108 \%$ (see Table 6). From worst to the optimistic scenario, a reduction in the number of referrals is observed. This is due to the decrease in the number of exacerbation-related admissions in the scenarios (as indicated in Table 6) associated with the effectiveness of the reduction in the rate of readmission under the PEPR programme.

On the other hand, in the worst-case scenario (no reduction in readmission), a considerable number of patients could not complete the PEPR programme due to readmissions to hospital. Therefore, even though most patients (1123) are referred to PEPR in the worst-case scenario, the number of patients completing PEPR is higher in all other scenarios.

Hospital Activity: The number of inpatient admissions, 30-day readmissions dropped by more than $10 \%$ and $30 \%$, respectively (see Table 6 ). Occupied bed days also reduced by $16 \%$ from 6249 to 5251 mainly due to reductions in readmission and LoS. Note that the number of occupied days is higher in the pessimistic scenario than worst-case scenario because the effect of PEPR on LoS is applicable for a shorter period - 3 months (duration of study in Eaton et al., 2009) vs 12 months (duration of study in Greeting et al., 2014).

Patient Outcome: Loss of QALY utility due to hospitalisation reduced by $10 \%$ due to the reduction in the admissions (baseline vs optimistic). Moreover, the improvement in quality of life via PR increased by double (more than $100 \%$ ) due to the increase in the number of patients completing the programme. 
Costing and Revenue: Although total PR cost increased by about $110 \%$, total cost of inpatient bed days and total cut on reimbursement (due to the 30-day readmission rule) remarkably decreased by $15 \%$ and $37 \%$, respectively, under the optimistic scenario. Lastly, about $5 \%$ reduction in hospital revenue was noticed, as fewer patients are admitted and cared for in hospital.

Staff related Results: The other positive effect of PEPR policy is on the service hours of clinicians and the reduction of costs, even if more service hours are needed for PR programmes (see Table 7). Nurse and consultant service hours go down by $14 \%$ and $11 \%$ respectively, whereas physiotherapist service hours are doubled (110\% increase) as more patients are referred to PR due to PEPR policy. The decrease in nurse and clinician hours compensates for the extra physiotherapist hours. Note that total staff hours and costs have decreased by $6 \%$ and $12 \%$ for realistic and optimistic scenario respectively, and almost at the same level for other scenarios as compared to the baseline. Thus, the hospital can allocate these available service hours and empty beds for elective patients waiting for surgery or intervention.

Cost-effectiveness Analysis: The scenario results are analysed, and the incremental costeffectiveness ratio (ICER) of PEPR is calculated for each scenario. The realistic and optimistic scenarios are found to be cost saving against the baseline (with more than $£ 26,000$ and $£ 160,000$ over a 3-year period, respectively), in addition to gained QALY utility of 26.65 and 27.81 (see Figure 5). The scenarios have negative ICERs (i.e. - £980 and $-£ 5,762$ per QALY, respectively) indicating high cost-effectiveness and the lower cost of treatments compared with the usual care.

On the other hand, in the worst and pessimistic cases, the costs increased by approximately $£ 137,000$ and $£ 158,000$ with a QALY utility increase of 23.34 and 25.62 , respectively. However, even in these cases, the scenarios (ICERs of $£ 5,886$ and $£ 6,172$ per QALY) are cost- 
effective as the NICE threshold for ICER per QALY is generally between $£ 20,000$ and $£ 30,000$ per QALY (NICE, 2018).

\section{Discussion}

The number of COPD patients is increasing and this trend is expected to continue in line with the structure and ageing of the UK population. In the absence of new and transformational therapies, this will create significant pressures on COPD and wider services within the NHS. Due to financial constraints in public services including the health and social care sector, innovative solutions are required to assess and respond to the needs of COPD patients, both now and in the future.

The current study is timely when the NHS in England is faced with severe challenges against this background. Many studies have evaluated the impact of new treatments, drugs, smoking cessation therapies for COPD mainly using MM and MCS, but a DES model has never been developed for the COPD patient pathway. The possibility of efficiency gains and exploring ways of improving outcomes can only be welcomed by patients and those responsible for the treatment and management of COPD. The evaluation of innovative treatment procedures could offer key decision makers insights about more effective ways of caring for COPD patients whilst maintaining and improving care quality.

The impact of PEPR policy is tested as a scenario which is also recommended by NICE (2016b) as a quality standard. According to our findings the use of PEPR leads to positive outcomes in terms of decreasing patient readmissions; reduction in total COPD treatment costs; reduction in staff workload; increased patient satisfaction in terms of patient outcomes, and decreased levels of activity, thus a reduction in hospital resource requirements. This is extremely useful because as more capacity is freed, it is a valuable opportunity for decreasing elective waiting 
times, which should not be longer than 18 weeks for non-urgent consultant-led treatments in the NHS. Freeing hospital beds by preventing avoidable demand are points of the NHS's 10 Point Efficiency Plan for improving efficiency and funding (NHS England, 2017).

The results indicate that the use of PEPR decreases emergency readmission, occupied bed days, service hours and the loss of QALY utility. The number of 30-day and 90-day readmission reduce by more than one-third as well as the cut on reimbursement due to 30-day readmission rule. Furthermore, inpatient admissions, occupied bed days, total professional service hours may drop by up to $10.3 \%, 16 \%$, and $10.8 \%$ respectively. Realistic and optimistic scenarios showed reduction in total cost in addition to increase in QALY utility. Even the worst case and pessimistic scenarios indicated that PEPR is cost-effective (ICERs: $£ 5,886$ per QALY and $£ 6,172$ per QALY), lower than NICE’s threshold for ICER (£20,000-£30,000 per QALY) by providing an increase in QALYs utility compared to baseline.

By incorporating the patient readmissions, the positive impact of the tested scenarios on the number of readmissions (i.e. 30-day and 90-day readmissions) is clearly shown in the outputs. Without the readmission component embedded into our simulation model, it is impossible for us to capture such an important phenomenon, as around 15\% of all COPD hospitalisations in UK are 30-day readmissions. Recall that the main idea of operational/patient pathway modelling is to enable users to track individuals` footsteps within the system. However, the inpatient or patient pathway models in the literature have surprisingly not covered this important issue, and most have not even mentioned about patient readmissions. We have therefore considered this crucial aspect of the patient pathway, so that our model generates all the required outputs. This enables key decision makers to test scenarios around improving patient readmissions as they are expected to increase/preserve their performance metrics. 
We noticed how important it is to test the same policy with different parameters, e.g. reduction in readmission, decrease in LoS, duration, and effective period of PEPR. Covering from worst to optimistic cases gave detailed information about the effects of the changes for key decision makers. We illustrated the effect of using different duration and reducing the rate of readmission on the number of completed PEPR and occupied bed days (fewer patients could complete the programme or more beds are used in the pessimistic scenario compare to worstcase scenario due to shorter study duration).

The current study underlines the importance of simulation modelling in the context of moving towards an evidence-based decision-making process. It has been observed that in many cases, healthcare decision makers have a very clear idea about the decisions to be made to improve quality of care and make better use of scarce resources, but they lacked the evidence to make a case to decision makers. This study provides that the required evidence, where simulation modelling fills an important gap, allowing a wide range of scenarios to be exhaustively tested and where possible implemented in practice with confidence and a vision about what is expected in the future.

Moreover, the model is not focused solely upon improving the COPD service but also on improving patient care quality with the goal of reducing readmission rates, a crucial indicator of hospital performance and patient outcomes. Therefore, this study can be regarded as a new approach for modelling COPD services.

\subsection{Implementation}

Increased use of PR nevertheless requires a financial investment, in the form of nurses and physiotherapist, space, administrative and planning activities. However, such investment is outweighed by the potential gains increase in QALY, reduction in service hours and bed occupancy outlined above. 
A major challenge is whether the hospital management team is prepared for such increase in the number of PR referrals (up to 127\%), an average of 4 new referral each week compared to baseline. The service needs to prepare an action plan in advance, e.g. referral criteria, resource allocations, and planning and scheduling, in order to cope with the demand and to run the PR programmes efficiently.

Firstly, the team needs to act smoothly and assess an individual patient's needs accordingly (after an exacerbation), e.g. if the patient is eligible for the programme. The team should ensure that patients are referred to and started on the PR programme in a timely fashion (within 7-10 days). Moreover, resources (staff, rooms, gym) need to be allocated accordingly to the scheduled programmes. More staff (e.g. physiotherapist, nurse, clerk) may be recruited in advance because the required physiotherapist service hours are expected to increase by up to $110 \%$.

Studies show that some patients are not eligible for the PR programme (about 30\%), which requires physical and mental practice, so other possible post-exacerbation interventions should be envisaged for those patients. Also, less than half of the referred patients complete the PR programme. Therefore, steps to increase the enrolment and completion rates can be considered by detecting and eliminating the reasons, e.g. educating patients, knowledge about PR, and transportation.

We recommend implementing the scenario, PEPR, as it has favourable outputs in terms of patient and operational aspects. The model is currently under implementation phase at RFH, where the study is carried out. However, the implementation is moving forward slower than expected as the provider has dedicated their entire workforce for treating severely ill COVID19 patients since the outbreak. 
The model was developed with the active engagement and involvement of staff at Royal Free Hospital. This positive relationship has facilitated the development of a user-friendly decision support tool (simulation software), lowering the technical challenges faced by healthcare professionals, further enabling them to play a more assertive role in building and using simulation models. By healthcare managers and professionals, several scenarios for better management of COPD patients can be tested with the existing model, such as vaccination, service closure, capacity reduction, medicine/treatment optimisation, screening policy, and increased use of CS.

\subsection{Future Work}

The simulation model has some limitations. As interventions such as lung volume reduction and lung transplants are performed at other hospitals, these are not included in the model. Also, CS can be conceptualised and integrated to the model, which plays a vital role in the management and treatment of COPD.

The model represents a single NHS Trust in London, which may have implications for generalisability of the results. The findings of the research are based on results obtained from the application of the DES to a single Trust (although large) in the UK. The positive impact of the use of PEPR can be generalised to other providers in the UK. It is possible that the optimal percentage of patients to be referred to PEPR may vary between providers due to varying patient numbers and the distribution of patients across the reasons for admission. The methodology and model are transferable to other COPD services in the UK, as the input parameters can be altered accordingly.

A simulation model is only a representation of a system and it is impossible to capture every detail, thus the results sometimes need to be interpreted with caution. As in most modelling exercises, whether a mathematical or simulation model, there are assumptions and 
simplifications. Increased complexity can be introduced if medical conditions in addition to COPD are included; socioeconomic status of patients; psychological aspects of patients, which may influence disease severity and the effectiveness of the treatment; advanced predictive models can be developed to predict patients at risk of first and subsequent readmissions, which could then be integrated to the simulation model accordingly. Furthermore, future research can also be directed towards integrating both the provider's and the patients' perspectives.

Acknowledgements - We would like to thank the following healthcare professionals for allocating their precious time and valuable input to build the COPD pathway: Dr Swapna Mandal, Stephen Byrd, Ailsa Carmichael, Anthony Geraets, Lisa Wordsworth, Abigail Greenwell (all Royal Free London NHS Foundation Trust); Travis Edwards, Bianca Nwaneri (all Central and North West London NHS Foundation Trust). Usame Yakutcan is thankful to the Hertfordshire Business School for making this study possible by waiving his tuition fees for this $\mathrm{PhD}$ study.

\section{REFERENCES}

Asukai, Y., Baldwin, M., Fonseca, T., Gray, A., Mungapen, L. \& Price, D. 2013. Improving clinical reality in chronic obstructive pulmonary disease economic modelling : development and validation of a micro-simulation approach. Pharmacoeconomics, $31(2), 151-61$.

Atsou, K., Chouaid, C. \& Hejblum, G. 2011. Simulation-based estimates of effectiveness and cost-effectiveness of smoking cessation in patients with chronic obstructive pulmonary disease. PLoS One, 6(9), e24870.

Atsou, K., Crequit, P., Chouaid, C. and Hejblum, G., 2016. Simulation-based estimates of the effectiveness and cost-effectiveness of pulmonary rehabilitation in patients with chronic obstructive pulmonary disease in France. PloS one, 11(6), p.e0156514.

Banks, J., Carson, J. S., Nelson, B. L. \& Nicol, D. 2005. Discrete-event system simulation, 4th edn. Englewood Cliffs: Prentice Hall.

Behnke, M., Taube, C., Kirsten, D., Lehnigk, B., Jorres, R.A., Magnussen, H. 2000. Homebased exercise is capable of preserving hospital-based improvements in severe chronic obstructive pulmonary disease. Respiratory Medicine, 94:1184-91.

BLF. 2011. Invisible lives: chronic obstructive pulmonary disease (COPD) finding the missing millions [Online]. British Lung Foundation (BLF). Available at: 
http://spirohub.com/wp-content/uploads/2016/01/BLF-Invisible-Lives-report.pdf [Accessed 28 May 2016].

Bonabeau, E. 2002. Agent-Based Modeling: Methods and Techniques for Simulating Human Systems. Proceedings of the National Academy of Sciences of the United States of America, 99(10), 7280-7287.

Borg, S., Ericsson, Å., Wedzicha, J., Gulsvik, A., Lundbäck, B., Donaldson, G. C., et al. 2004. A Computer Simulation Model of the Natural History and Economic Impact of Chronic Obstructive Pulmonary Disease. Value in Health, 7(2), 153-167.

Brailsford, S. \& Schmidt, B. 2003. Towards incorporating human behaviour in models of health care systems: An approach using discrete event simulation. European Journal of Operational Research, 150(1), 19-31.

Brailsford, S. C. 2007. Tutorial: Advances and challenges in healthcare simulation modeling. Proceedings of the 2007 Winter Simulation Conference, Vols 1-5, 1415-1427.

Brailsford, S. C., Gutjahr, W. J., Rauner, M. S. \& Zeppelzauer, W. 2007. Combined Discreteevent Simulation and Ant Colony Optimisation Approach for Selecting Optimal Screening Policies for Diabetic Retinopathy. Computational Management Science, $4(1), 59-83$.

Britton M., 2003. The burden of COPD in the U.K.: results from the Confronting COPD survey. Respir Med; 97(Suppl C):S71-S79.

Caro, J. J., Guo, S., Ward, A., Chalil, S., Malik, F. \& Leyva, F. 2006. Modelling the economic and health consequences of cardiac resynchronization therapy in the UK. Current Medical Research and Opinion, 22(6), 1171-1179.

Chahal, K. \& Eldabi, T. 2008. Applicability of hybrid simulation to different modes of governance in UK healthcare. Proceedings of the 2008 Winter Simulation Conference, 7-10 Dec. 2008. 1469-1477.

Charfeddine, M. \& Montreuil, B. 2010. Integrated agent-oriented modeling and simulation of population and healthcare delivery network: Application to COPD chronic disease in a Canadian region. Proceedings of the 2010 Winter Simulation Conference, 5-8 Dec. 2010. 2327-2339.

Chemweno, P., Thijs, V., Pintelon, L. \& Van Horenbeek, A. 2014. Discrete event simulation case study: Diagnostic path for stroke patients in a stroke unit. Simulation Modelling Practice and Theory, 48, 45-57.

Comas, M., Arrospide, A., Mar, J., Sala, M., Vilaprinyo, E., Hernandez, C., et al. 2014. Budget impact analysis of switching to digital mammography in a population-based breast cancer screening program: a discrete event simulation model. PLoS One, 9(5), e97459.

Cooper, C. 2014. Exclusive: NHS faces financial disaster in 2015 as politicians urged to find radical solution [Online]. Independent. Available at: http://www.independent.co.uk/life-style/health-and-families/health-news/exclusivenhs-faces-financial-disaster-in-2015-as-politicians-urged-to-find-radical-solution9259915.html [Accessed 15 May 2016]. 
Cooper, K., Davies, R., Roderick, P., Chase, D. \& Raftery, J. 2002. The development of a simulation model of the treatment of coronary heart disease. Health Care Management Science, 5(4), 259-267.

Crossan, C., Lord, J., Ryan, R., Nherera, L. and Marshall, T. (2017) 'Cost effectiveness of casefinding strategies for primary prevention of cardiovascular disease: a modelling study', Br J Gen Pract, 67(654), pp. e67-e77.

Curtis, L. 2013. Unit Costs of Health and Social Care 2013 [Online]. Personal Social Services Research Unit, University of Kent, Canterbury. Available at: https://www.pssru.ac.uk/pub/uc/uc2013/full-with-covers.pdf [Accessed: 02 June 2018].

Davies, R., Roderick, P., Canning, C. \& Brailsford, S. 2002. The evaluation of screening policies for diabetic retinopathy using simulation. Diabetic Medicine, 19(9), 762-770.

Demir, E. and Southern, D., 2017. Enabling better management of patients: discrete event simulation combined with the STAR approach. Journal of the Operational Research Society, 68(5), pp.577-590.

Demir, E., Southern, D., Rashid, S. and Lebcir, R. 2018. A discrete event simulation model to evaluate the treatment pathways of patients with cataract in the United Kingdom. BMC health services research, 18(1), pp. 933.

Department of Health. 2011. An outcomes strategy for people with chronic obstructive pulmonary disease (COPD) and asthma in England [Online]. Available at: https://www.gov.uk/government/uploads/system/uploads/attachment_data/file/216139 /dh_128428.pdf [Accessed 10 March 2016].

Department of Health. 2012. A simple guide to Payment by Results [Online]. Available at: https://assets.publishing.service.gov.uk/government/uploads/system/uploads/attachme nt_data/file/213150/PbR-Simple-Guide-FINAL.pdf [Accessed 27 November 2018].

Department of Health. 2013. Payment by Results in the NHS: tariff for 2012 to 2013 [Online]. Available at: https://www.gov.uk/government/publications/confirmation-of-paymentby-results-pbr-arrangements-for-2012-13 [Accessed 13 June 2018].

Department of Health. 2015. Reviewing the indicators in the Public Health Outcome Framework [Online]. Available at: https://www.gov.uk/government/consultations/reviewing-the-indicators-in-the-publichealth-outcome-framework [Accessed 27 May 2016].

Eaton T, Young P, Fergusson W, Moodie L, Zeng I, O’Kane F, ... \& Kolbe J. 2009. Does early pulmonary rehabilitation reduce acute healthcare utilization in COPD patients admitted with an exacerbation? A randomized controlled study. Respirology, 14:230-8.

Fone, D., Hollinghurst, S., Temple, M., Round, A., Lester, N., Weightman, A., et al. 2003. Systematic review of the use and value of computer simulation modelling in population health and health care delivery. Journal of Public Health Medicine, 25(4), 325-335.

Friebel, R., Hauck, K., Aylin, P. and Steventon, A. 2018. National trends in emergency readmission rates: a longitudinal analysis of administrative data for England between 2006 and 2016. BMJ open, 8(3), pp. e020325. 
Getsios, D., Blume, S., Ishak, K. J., Maclaine, G. \& Hernandez, L. 2012. An economic evaluation of early assessment for Alzheimer's disease in the United Kingdom. Alzheimers Dement, 8(1), 22-30.

Getsios, D., Marton, J. P., Revankar, N., Ward, A. J., Willke, R. J., Rublee, D., et al. 2013. Smoking cessation treatment and outcomes patterns simulation: a new framework for evaluating the potential health and economic impact of smoking cessation interventions. Pharmacoeconomics, 31(9), 767-780.

GOLD. 2018. Global Strategy for Diagnosis, Management, and Prevention of Chronic Obstructive Pulmonary Disease [Online]. Global Initiative for Chronic Obstructive Lung Disease (GOLD). Available at: https://goldcopd.org/wpcontent/uploads/2017/11/GOLD-2018-v6.0-FINAL-revised-20-Nov WMS.pdf

[Accessed 12 April 2018].

Greening, N. J., Williams, J. E., Hussain, S. F., Harvey-Dunstan, T. C., Bankart, M. J., Chaplin, E. J., ... \& Steiner, M. C. 2014. An early rehabilitation intervention to enhance recovery during hospital admission for an exacerbation of chronic respiratory disease: randomised controlled trial. BMJ, 349, g4315.

Gunal, M. M. 2012. A guide for building hospital simulation models. Health Systems, 1(1), 1725.

Gunal, M. M. \& Pidd, M. 2010. Discrete event simulation for performance modelling in health care: a review of the literature. Journal of Simulation, 4(1), 42-51.

Harper, P. R., Sayyad, M. G., de Senna, V., Shahani, A. K., Yajnik, C. S. \& Shelgikar, K. M. 2003. A systems modelling approach for the prevention and treatment of diabetic retinopathy. European Journal of Operational Research, 150(1), 81-91.

Hollmann, M., Garin, O., Galante, M., Ferrer, M., Dominguez, A. and Alonso, J., 2013. Impact of influenza on health-related quality of life among confirmed (H1N1) 2009 patients. PloS one, 8(3), p.e60477.

Hoogendoorn, M., Ramos, I. C., Baldwin, M., Guix, N. G.-R. and Rutten-van Mölken, M. P. 2019. Broadening the perspective of cost-effectiveness modeling in chronic obstructive pulmonary disease: a new patient-level simulation model suitable to evaluate stratified medicine. Value in Health, 22(3), pp. 313-321.

Hoogendoorn, M., Rutten-van Molken, M. P., Hoogenveen, R. T., Al, M. J. \& Feenstra, T. L. 2011. Developing and applying a stochastic dynamic population model for chronic obstructive pulmonary disease. Value in Health, 14(8), 1039-1047.

Hurst, J. R., Vestbo, J., Anzueto, A., Locantore, N., Müllerova, H., Tal-Singer, R., ... \& Calverley, P. 2010. Susceptibility to exacerbation in chronic obstructive pulmonary disease. New England Journal of Medicine, 363(12), 1128-1138.

Igarashi, A., Goto, R., Suwa, K., Yoshikawa, R., Ward, A. J. \& Moller, J. 2016. CostEffectiveness Analysis of Smoking Cessation Interventions in Japan Using a DiscreteEvent Simulation. Applied Health Economics and Health Policy, 14(1), 77-87. 
Karnon, J. \& Afzali, H.H.A. 2014. When to use discrete event simulation (DES) for the economic evaluation of health technologies? A review and critique of the costs and benefits of DES. Pharmacoeconomics, 32(6), 547-558.

Ko, F. W., Cheung, N. K., Rainer, T. H., Lum, C., Wong, I., \& Hui, D. S. 2017. Comprehensive care programme for patients with chronic obstructive pulmonary disease: a randomised controlled trial. Thorax, 72(2), 122-128.

Ko, F. W., Ngai, J. C., Ng, S. S., Chan, K. P., Cheung, R., Leung, M. Y., ... \& Hui, D. S. 2014. COPD care programme can reduce readmissions and in-patient bed days. Respiratory medicine, 108(12), 1771-1778.

Law, A. M. and Kelton, W. D. 2000. Simulation modeling and analysis. McGraw-Hill New York.

Le Lay, A., Despiegel, N., François, C. \& Duru, G. 2006. Can discrete event simulation be of use in modelling major depression? Cost Effectiveness and Resource Allocation, 4(1), $1-11$.

Lebcir, R., Demir, E., Ahmad, R., Vasilakis, C. and Southern, D., 2017. A discrete event simulation model to evaluate the use of community services in the treatment of patients with Parkinson's disease in the United Kingdom. BMC health services research, 17(1), p.50.

Lewko, A., Harlow, S.K., MacDonald, P. and Irvin-Sellers, M., 2015. Effects of post exacerbation pulmonary rehabilitation (PEPR) on exercise tolerance, quality of life (QoL), anxiety, depression and healthcare utilisation. European Respiratory Journal, 46(suppl 59), p.OA478.

Macnabb, J., Rowan, L., Heneghan, C. \& Onakpoya, I. 2014. How England's emergency departments are being penalised. $B M J, 348, \mathrm{~g} 1604$.

Man, W.D., Polkey, M.I., Donaldson, N., et al. 2004. Community pulmonary rehabilitation after hospitalisation for acute exacerbations of chronic obstructive pulmonary disease: randomised controlled study. BMJ, 329:1209.

Mar, J., Arrospide, A. \& Comas, M. 2010. Budget impact analysis of thrombolysis for stroke in Spain: a discrete event simulation model. Value in Health, 13(1), 69-76.

Mathwave. 2017. EasyFit - Distribution Fitting Made Easy. [Online]. Available at: http://www.mathwave.com/ [Accessed 15 June 2018].

Mayorga, M. E., Reifsnider, O. S., Wheeler, S. B. \& Kohler, R. E. 2014. A discrete event simulation model to estimate population level health and economic impacts of smoking cessation interventions. Proceedings of the 2014 Winter Simulation Conference. Savannah, Georgia: IEEE Press.

McKenzie, F. E., Wong, R. C. \& Bossert, W. H. 1998. Discrete-Event Simulation Models of Plasmodium falciparum Malaria. Simulation, 71(4), 250-261.

Menn, P., Leidl, R. \& Holle, R. 2012. A lifetime Markov model for the economic evaluation of chronic obstructive pulmonary disease. Pharmacoeconomics, 30(9), 825-840. 
NACAP. 2017. Outcomes from the Pulmonary Rehabilitation COPD Audit 2015 Findings and quality improvement. [Online]. National Chronic Obstructive Pulmonary Disease (COPD) Audit Programme (NACAP). Available at: https://www.rcplondon.ac.uk/projects/outputs/pulmonary-rehabilitation-beyondbreathing-better [Accessed 10 August 2018].

Najafzadeh, M., Marra, C. A., Lynd, L. D., Sadatsafavi, M., FitzGerald, J. M., McManus, B. and Sin, D. 2012. Future impact of various interventions on the burden of COPD in Canada: a dynamic population model, PloS one, 7(10), pp. e46746.

NHS England. 2017. Next steps on the NHS five year forward view. [Online]. Available at: https://www.england.nhs.uk/wp-content/uploads/2017/03/NEXT-STEPS-ON-THENHS-FIVE-YEAR-FORWARD-VIEW.pdf [Accessed 15 October 2018].

NHS Improvement. 2016. 2017/18 and 2018/19 National Tariff Payment System. [Online]. Available at: https://improvement.nhs.uk/documents/1044/2017-18 and 201819 National_Tariff_Payment_System.pdf [Accessed 10 June 2018].

NHS Improvement. 2018. Reference costs 2017/18: highlights, analysis and introduction to the data. Available at: https://improvement.nhs.uk/documents/1972/1_Reference costs_201718.pdf [Accessed: 10 December 2019].

NICE. 2016a. COPD overview. Available at: https://pathways.nice.org.uk/pathways/chronicobstructive-pulmonary-disease [Accessed 20 October 2016].

NICE. 2016b. National Institute for Health and Care Excellence. Chronic obstructive pulmonary disease in adults. NICE quality standard QS10. Updated Feb 2016. Available at: https:/www.nice.org.uk/guidance/qs10/chapter/Quality-statement-5Pulmonary-rehabilitation-after-an-acute-exacerbation [Accessed 11 March 2018].

NICE. 2018. Guide to the Processes of Technology Appraisal. National Institute for Health and Care Excellence (NICE) Available at: https://www.nice.org.uk/Media/Default/About/what-we-do/NICE-guidance/NICEtechnology-appraisals/technology-appraisal-processes-guide-apr-2018.pdf [Accessed: 20 September 2019].

Nielsen, R., Johannessen, A., Benediktsdottir, B., Gislason, T., Buist, A. S., Gulsvik, A., et al. 2009. Present and future costs of COPD in Iceland and Norway: results from the BOLD study. European Respiratory Journal, 34(4), 850-857.

OECD/EU 2016, Health at a Glance: Europe 2016 - State of Health in the EU Cycle, OECD Publishing, Paris. http://dx.doi.org/10.1787/9789264265592-en.

Oostenbrink, J. B., Rutten-van Molken, M. P., Monz, B. U. \& FitzGerald, J. M. 2005. Probabilistic Markov model to assess the cost-effectiveness of bronchodilator therapy in COPD patients in different countries. Value in Health, 8(1), 32-46.

Pan, F., Reifsnider, O., Zheng, Y., Proskorovsky, I., Li, T., He, J. and Sorensen, S. V. 2018. Modeling clinical outcomes in prostate cancer: application and validation of the discrete event simulation approach. Value in Health, 21(4), pp. 416-422.

Pitt, M., Monks, T., Chalk, D. 2013. NICE Guideliness TSU Interim methods guide for developing service guidance 2013: Appendix 2: Service Delivery Operational Research 
Methods. Available at: https:/www.nice.org.uk/Media/Default/About/what-wedo/NICE-guidance/NICE-guidelines/Clinical-guidelines/Interim-methods-guide-fordeveloping-service-guidance-2013-appendix-2.pdf [Accessed: 10 September 2019].

Puhan, M. A., Gimeno-Santos, E., Cates, C. J., \& Troosters, T. 2016. Pulmonary rehabilitation following exacerbations of chronic obstructive pulmonary disease. The Cochrane Library.

Ramwadhdoebe, S., Buskens, E., Sakkers, R. J. B. \& Stahl, J. E. 2009. A tutorial on discreteevent simulation for health policy design and decision making: Optimizing pediatric ultrasound screening for hip dysplasia as an illustration. Health Policy, 93(2-3), 143150.

Rauner, M. S., Brailsford, S. C. \& Flessa, S. 2005. Use of Discrete-Event Simulation to Evaluate Strategies for the Prevention of Mother-to-Child Transmission of HIV in Developing Countries. The Journal of the Operational Research Society, 56(2), 222233.

Roberts, S.E., Kodumooru, N., Purcell, S., Williamson, A., Broomfield, H., Restrick, L.J. and Stern, M., 2013. P118 Post discharge pulmonary rehabilitation for acute exacerbation COPD does not always reduce re-admission rates. Thorax, 68(Suppl 3), pp.A128A128.

Robinson, S., 2004. Simulation: the practice of model development and use. Chichester: Wiley.

Sadatsafavi, M., Ghanbarian, S., Adibi, A., Johnson, K., FitzGerald, J. M., Flanagan, W., Bryan, S., Sin, D. and Network, C. R. R. 2019. Development and validation of the Evaluation Platform In COPD (EPIC): a population-based outcomes model of COPD for Canada. Medical Decision Making, 39(2), pp. 152-167.

Seymour, John M., et al. 2010. Outpatient pulmonary rehabilitation following acute exacerbations of COPD. Thorax 65.5, 423-428.

Simpson, K. N., Strassburger, A., Jones, W. J., Dietz, B. \& Rajagopalan, R. 2012. Comparison of Markov Model and Discrete-Event Simulation Techniques for HIV. Pharmacoeconomics, 27(2), 159-165.

Sin, D. D., Golmohammadi, K. \& Jacobs, P. 2004. Cost-effectiveness of inhaled corticosteroids for chronic obstructive pulmonary disease according to disease severity. The American Journal of Medicine, 116(5), 325-331.

Sg2 2011. Sg2 Service kit Reducing 30-Day Emergency Readmissions. [Online]. Available at:https://www.hsj.co.uk/Uploads/2/Files/2011/6/15/Sg2_Service\%20Kit_Reducing\% 2030-Day\%20Readmissions.pdf [Accessed 28 November 2018].

Spencer, M., Briggs, A. H., Grossman, R. F. \& Rance, L. 2005. Development of an economic model to assess the cost effectiveness of treatment interventions for chronic obstructive pulmonary disease. Pharmacoeconomics, 23(6), 619-637.

Tan, E., Boessen, R., Fishwick, D., Klein Entink, R., Meijster, T., Pronk, A., et al. 2015. A microsimulation model for the development and progression of chronic obstructive pulmonary disease. Respiratory Medicine, 109(12), 1521-1531. 
Tian, Y., Dixon, A., \& Gao, H. 2012. Emergency hospital admissions for ambulatory caresensitive conditions: identifying the potential for reductions. The King's Fund, 1-13.

Trueman, D., Woodcock, F., \& Hancock, E. 2017. Estimating the economic burden of respiratory illness in the UK [Online]. Available at: https://www.probonoeconomics.com/sites/default/files/files/British\%20Lung\%20Fou ndation\%20full\%20report\%2015032017_0.pdf [Accessed 22 May 2018].

Viana, J., Brailsford, S. C., Harindra, V. \& Harper, P. R. 2014. Combining discrete-event simulation and system dynamics in a healthcare setting: A composite model for Chlamydia infection. European Journal of Operational Research, 237(1), 196-206.

Vieira, I. T., Harper, P. R., Shahani, A. K. \& Senna, V. d. 2003. Mother-to-Child Transmission of HIV: A Simulation-Based Approach for the Evaluation of Intervention Strategies. The Journal of the Operational Research Society, 54(7), 713-722.

Ward, A., Bozkaya, D., Fleischmann, J., Dubois, D., Sabatowski, R. \& Caro, J. J. 2007. Modeling the economic and health consequences of managing chronic osteoarthritis pain with opioids in Germany: comparison of extended-release oxycodone and OROS hydromorphone. Current Medical Research and Opinion, 23(10), 2333-2345.

Xenakis, J. G., Kinter, E. T., Ishak, K. J., Ward, A. J., Marton, J. P., Willke, R. J., et al. 2011. A Discrete-Event Simulation of Smoking-Cessation Strategies Based on Varenicline Pivotal Trial Data. Pharmacoeconomics, 29(6), 497-510.

Zhang, X. 2018. Application of discrete event simulation in health care: a systematic review. BMC health services research, 18(1), pp. 687. 
Table 1 A Selected Sub-set of the Input Parameters

\begin{tabular}{|c|c|c|c|}
\hline Parameter & Estimate & Distribution & Data Source \\
\hline \multicolumn{4}{|c|}{ Treatment pathway (in Outpatient Department and Outpatient Services) } \\
\hline $\begin{array}{c}\text { Number of new patient arrivals to Outpatient } \\
\text { department per week }\end{array}$ & {$[6,8]$} & Uniform & Local data \\
\hline Yearly increase in new patients & $5.40 \%$ & Fixed & HES Data \\
\hline $\begin{array}{c}\text { Percentage of new patients in the department falling } \\
\text { into each disease severity }\end{array}$ & $\begin{array}{c}\text { Mild: } 11 \% \\
\text { Moderate: } 35 \% \\
\text { Severe: } 27 \% \\
\text { Very Severe: } 27 \% \\
\end{array}$ & Multinomial & Local Data \\
\hline $\begin{array}{l}\text { Percentage of new patients having a first } \\
\text { appointment in COPD Clinic }\end{array}$ & {$[30 \%, 35 \%]$} & Uniform & Local Expert \\
\hline $\begin{array}{l}\text { Attendance rate in COPD Clinic for FA and FU } \\
\text { appointments }\end{array}$ & $\begin{array}{l}\text { FA: } 85 \% \\
\text { FU: } 70 \%\end{array}$ & Bernoulli & Local Expert \\
\hline Required mix of resources for COPD Clinic & $\begin{array}{l}\text { A consultant, a HCA, and a } \\
\text { room }\end{array}$ & Fixed & Local Expert \\
\hline $\begin{array}{l}\text { Treatment time in COPD Clinic for First and FU } \\
\text { appointments (per patient) }\end{array}$ & $\begin{array}{l}\text { FA: }[30-45] \text { minutes } \\
\text { FU: }[15-20] \text { minutes }\end{array}$ & Uniform & Local Expert \\
\hline $\begin{array}{l}\text { Time between previous and FU appointment in } \\
\text { COPD Clinic }\end{array}$ & 6 months & Fixed & Local Expert \\
\hline $\begin{array}{l}\text { Percentage of new patients given a FU appointment } \\
\text { in each clinic }\end{array}$ & $\begin{array}{c}\text { COPD: } 65 \% \\
\text { General: } 95 \% \\
\text { NIV: } 50 \% \\
\text { Alpha-1: } 95 \% \\
\text { Advanced: } 40 \%\end{array}$ & Bernoulli & Local Expert \\
\hline $\begin{array}{c}\text { Percentage of patients referred to Pulmonary } \\
\text { Rehabilitation }\end{array}$ & {$[3 \%, 5 \%]$} & Uniform & Local Expert \\
\hline \multicolumn{4}{|c|}{ Treatment pathway (in A\&E Department and Inpatient Department) } \\
\hline Treatment time in A\&E & $\begin{array}{l}\text { Alpha1: 4.1129, Alpha2: } \\
\text { 17.322, Beta: } 802.41\end{array}$ & Pearson VI & HES Data \\
\hline Waiting Time for Elective Appointment & Alpha: 0.43611, Beta: 111.85 & Gamma & HES Data \\
\hline $\begin{array}{l}\text { Percentage of patients referred ICU falling into each } \\
\text { disease type, i.e. J40, J41, J42, J43, and J44 }\end{array}$ & $\begin{array}{c}\text { J40: } 2.3 \% \\
\text { J41: } 0 \% \\
\text { J42: } 0 \% \\
\text { J43: } 7.8 \% \\
\text { J44: } 5.2 \% \\
\end{array}$ & Bernoulli & HES Data \\
\hline $\begin{array}{l}\text { Percentage of J44 patients falling into each HRG } \\
\text { code }\end{array}$ & $\begin{array}{l}\text { DZ21A: } 18 \% \\
\text { DZ21B: } 0 \% \\
\text { DZ21C: } 0 \% \\
\text { DZ21D: } 0 \% \\
\text { DZ21E: } 2 \% \\
\text { DZ21F: } 1 \% \\
\text { DZ21G: } 0 \% \\
\text { DZ21H: } 31 \% \\
\text { DZ21J: } 35 \% \\
\text { DZ21K: } 3 \% \\
\text { Other: } 10 \%\end{array}$ & Multinomial & HES Data \\
\hline $\begin{array}{l}\text { Length of stay in inpatient department by disease } \\
\text { type (days) }\end{array}$ & $\begin{array}{l}\text { Frequency distribution } \\
\text { (Average: ?? days) }\end{array}$ & Frequency & HES Data \\
\hline $\begin{array}{l}\text { Care hours per patient day in Respiratory Ward (in } \\
\text { hours) }\end{array}$ & $\begin{array}{l}\text { Consultant: } 0.4 \\
\text { Nurse: } 4.82 \\
\end{array}$ & Fixed & $\begin{array}{l}\text { NHS Improvement } \\
(2018) \\
\end{array}$ \\
\hline $\begin{array}{l}\text { Risk of second emergency admission (for each } \\
\text { disease type) }\end{array}$ & $\begin{array}{c}\text { J40: } 30.62 \% \\
\text { J41: } 0 \% \\
\text { J42: } 0 \% \\
\text { J43: } 26.91 \% \\
\text { J44: } 28.96 \%\end{array}$ & Bernoulli & HES Data \\
\hline
\end{tabular}




\begin{tabular}{|c|c|c|c|}
\hline Revenues and Costs & Fixed & $\begin{array}{c}\text { National Tariff } \\
\text { Payment }\end{array}$ \\
\hline First Attendance - Single Professional $(\mathfrak{f})^{*}$ & DZ21A: 475 & & \\
& DZ21B: 3718 & & \\
& DZ21C: 2621 & & \\
& DZ21D: 2000 & & National Tariff \\
& DZ21E: 3684 & \multirow{2}{*}{ Fixed } & Payment \\
& DZ21F: 2678 & & \\
& DZ21G: 2168 & & \\
& DZ21H: 3819 & & \\
& DZ21J: 2475 & & \\
& DZ21K: 1849 & & \\
& Other: 1919 & & \\
& 59.36 & Fixed & Curtis (2013) \\
\hline
\end{tabular}

Notes: A\&E: Accident \& Emergency; COPD: Chronic obstructive pulmonary disease; FA: First Attendance; FU: Follow-up; GP: General Practitioner; HCA: Healthcare assistant; HRG: Healthcare Research Group; ICU: Intensive Care Unit; NIV: Non-Invasive Ventilation

*The values are updated each year. The first year's values are listed. 
Table 2 Disease Severity Transition Matrix. GOLD: Global Initiative for COPD.

\begin{tabular}{|c|c|c|c|c|c|}
\hline From/To & GOLD 1 & GOLD 2 & GOLD 3 & GOLD 4 & Death \\
\hline GOLD 1 & 0.925 & 0.030 & - & - & 0.046 \\
\hline GOLD 2 & - & 0.859 & 0.068 & - & 0.073 \\
\hline GOLD 3 & - & - & 0.831 & 0.058 & 0.111 \\
\hline GOLD 4 & - & - & - & 0.873 & 0.127 \\
\hline
\end{tabular}

Notes: GOLD 1: Mild, GOLD 2: Moderate, GOLD 3: Severe, GOLD 4: Very Severe 
Table 3 The validation results for the simulation model.

\begin{tabular}{|c|cccc|}
\hline Output parameters & $\begin{array}{c}\text { Actual } \\
\text { Data }\end{array}$ & $\begin{array}{c}\text { Simulation } \\
\text { results } \\
\text { (95\% LCI, UCI) }\end{array}$ & Deviation & $\begin{array}{c}\text { Difference in } \\
\text { Percentage (\%) }\end{array}$ \\
\hline FUP/NP Ratio & 2.7 & $\begin{array}{c}2.69 \\
(2.67,2.72)\end{array}$ & $\begin{array}{c}-0.01 \\
(-0.03,0.02)\end{array}$ & $\begin{array}{c}-0.25 \% \\
(-1.11 \%, 0.74 \%)\end{array}$ \\
\hline $\begin{array}{c}\text { Average Time Spent } \\
\text { in A\&E }\end{array}$ & 4.64 & 4.67 & 0.03 & $0.65 \%$ \\
& & $15.54,4.80)$ & $(-0.1,0.16)$ & $(-2.16 \%, 3.45 \%)$ \\
30-Day Readmission \\
Rate & $15.26 \%$ & $(14.58 \%$, & $(-0.68 \%$, & $1.90 \%$ \\
& & $16.53 \%)$ & $1.27 \%)$ & $(-4.46 \%, 8.32 \%)$ \\
\hline
\end{tabular}

LCI: Lower Confidence Interval, UCI: Upper Confidence Interval, FUP: Follow-up, NP: New Patient, A\&E: Accident \& Emergency. 
Table 4 The parameter values of the Fixed-Sample-Size procedure for replication number.

\begin{tabular}{|c|c|c|}
\hline Parameters & $\begin{array}{c}\text { Number of } \\
\text { Appointments in } \\
\text { the clinics }\end{array}$ & $\begin{array}{c}\text { Average Time spent in } \\
\text { Accident \& Emergency } \\
\text { Department }\end{array}$ \\
\hline Average $(\overline{\mathbf{X}})$ & 4072.6 & 4.67 \\
\hline Standard deviation (S) & 74.12 & 0.13 \\
\hline Required Minimum Replication Number (i) & 10 & 10 \\
\hline$t_{i-1,1-\alpha / 2}\left(t_{9,0.025}\right)$ & 2.26 & 2.26 \\
\hline Initial Replication Number (n) ${ }^{a}$ & 10 & 10 \\
\hline Relative error $(\mathrm{V})^{\mathrm{a}}$ & 0.15 & 0.15 \\
\hline Adjusted relative error $\left(\mathrm{V}^{\prime}\right)$ & 0.13 & 0.13 \\
\hline$n *(\gamma)$ & 0.013 & 0.020 \\
\hline
\end{tabular}

${ }^{\mathrm{a}}$ : Recommended baseline values for $\mathrm{n}$ and $\mathrm{V}$ by Law and Kelton (2000) 
Table 5 Parameters under worst, pessimistic, realistic and optimistic scenarios.

\begin{tabular}{|c|c|c|c|c|c|}
\hline & Baseline & $\begin{array}{c}\text { Worst } \\
\text { (Greening et } \\
\text { al., 2014) }\end{array}$ & $\begin{array}{l}\text { Pessimistic } \\
\text { (Eaton et al., } \\
\text { 2009) }\end{array}$ & $\begin{array}{l}\text { Realistic } \\
\text { (Puhan et } \\
\text { al., 2016) }\end{array}$ & $\begin{array}{c}\text { Optimistic } \\
\text { (Ko et al., } \\
2017 \text { and } \\
\text { Lewko et al., } \\
2015 \text { ) }\end{array}$ \\
\hline $\begin{array}{l}\text { Reduction in } \\
\text { Readmission }\end{array}$ & $0 \%$ & $0 \%$ & $25 \%$ & $38 \%$ & $50 \%$ \\
\hline Decrease in LoS & $0 \%$ & $18 \%$ & $18 \%^{\mathrm{a}}$ & $25 \%^{\mathrm{b}}$ & $40 \%$ \\
\hline Follow-up Duration & NA & 12 months & 3 months & 9 months & 12 months \\
\hline Effective period of PEPR & $\mathrm{NA}$ & 6 months* & 6 months* & 12 months* & 12 months* \\
\hline
\end{tabular}

LoS: Length of Stay, PEPR: Post-exacerbation Pulmonary Rehabilitation.

* Set via the meeting with the COPD team; a. Greening et al., 2014; b. Ko et al., 2014. 
Table 6 The impact of PEPR policy on operational and patient outcomes. Figures in brackets are the $95 \%$ confidence intervals.

\begin{tabular}{|c|c|c|c|c|c|}
\hline & Baseline & Worst & Pessimistic & Realistic & Optimistic \\
\hline \multicolumn{6}{|l|}{ PR Activity } \\
\hline Total PR Referral & $495(471,520)$ & $\begin{array}{c}1123(1066, \\
1181)\end{array}$ & $\begin{array}{c}1114(1060, \\
1169)\end{array}$ & $\begin{array}{c}1072(1029, \\
1114)\end{array}$ & $\begin{array}{c}1054(1007, \\
1100)\end{array}$ \\
\hline $\begin{array}{c}\text { Total Completed } \\
\text { PR }\end{array}$ & $283(267,297)$ & $575(546,604)$ & $596(567,624)$ & $584(562,606)$ & $589(564,614)$ \\
\hline \multicolumn{6}{|c|}{ Hospital Activity } \\
\hline $\begin{array}{c}\text { Number of } \\
\text { Inpatient Admission }\end{array}$ & $\begin{array}{c}1091(1063, \\
1118)\end{array}$ & $\begin{array}{c}1090(1058, \\
1123)\end{array}$ & $\begin{array}{c}1070(1050, \\
1091)\end{array}$ & $\begin{array}{c}1003(982 \\
1025)\end{array}$ & $979(962,996)$ \\
\hline $\begin{array}{c}\text { Number of } \\
\text { Occupied Bed Days }\end{array}$ & $\begin{array}{c}6249(6069, \\
6430)\end{array}$ & $\begin{array}{c}6003(5839 \\
6167)\end{array}$ & $\begin{array}{c}6022(5853 \\
6191)\end{array}$ & $\begin{array}{l}5591(5401 \\
5781)\end{array}$ & $\begin{array}{l}5251(5099, \\
5402)\end{array}$ \\
\hline $\begin{array}{c}\text { Exacerbation } \\
\text { Related Admission }\end{array}$ & $902(878,927)$ & $902(875,929)$ & $888(873,903)$ & $829(810,847)$ & $802(788,816)$ \\
\hline $\begin{array}{l}\text { Number of 30-day } \\
\text { Readmission }\end{array}$ & $170(156,183)$ & $169(152,186)$ & $147(135,160)$ & $124(110,139)$ & $111(102,121)$ \\
\hline \multicolumn{6}{|c|}{ Patient Outcome } \\
\hline $\begin{array}{c}\text { Loss of QALY } \\
\text { utility due to } \\
\text { Hospitalisation }\end{array}$ & $\begin{array}{c}32.7(31.9 \\
33.5)\end{array}$ & $\begin{array}{c}32.7(31.7 \\
33.7)\end{array}$ & $\begin{array}{c}32.1(31.5 \\
32.7)\end{array}$ & $\begin{array}{c}30.1(29.5 \\
30.7)\end{array}$ & $\begin{array}{c}29.4(28.9, \\
29.9)\end{array}$ \\
\hline $\begin{array}{c}\text { Gained QALY } \\
\text { utility due to PR }\end{array}$ & $\begin{array}{c}22.7(21.6 \\
23.8)\end{array}$ & $46(43.7,48.3)$ & $\begin{array}{l}47.7(45.4 \\
50.0)\end{array}$ & $\begin{array}{c}46.7(44.9, \\
48.5)\end{array}$ & $\begin{array}{c}47.1(45.1 \\
49.2)\end{array}$ \\
\hline \multicolumn{6}{|c|}{ Costing and Revenue } \\
\hline Total PR Cost & $\begin{array}{l}£ 207,049 \\
(£ 196,971, \\
£ 217,126)\end{array}$ & $\begin{array}{l}£ 425,386 \\
(£ 404,038, \\
£ 446,735)\end{array}$ & $\begin{array}{l}£ 438,852 \\
(£ 417,832, \\
£ 459,871)\end{array}$ & $\begin{array}{r}£ 429,090 \\
(£ 412,635, \\
£ 445,544)\end{array}$ & $\begin{array}{r}£ 431,699 \\
(£ 413,149, \\
£ 450,249)\end{array}$ \\
\hline $\begin{array}{c}\text { Total Cost of } \\
\text { Inpatient Bed days }\end{array}$ & $\begin{array}{l}£ 1.730 \mathrm{M} \\
(£ 1.680 \mathrm{M}, \\
£ 1.780 \mathrm{M})\end{array}$ & $\begin{array}{l}£ 1.662 \mathrm{M} \\
(£ 1.617 \mathrm{M}, \\
£ 1.707 \mathrm{M})\end{array}$ & $\begin{array}{l}£ 1.667 \mathrm{M} \\
(£ 1.620 \mathrm{M}, \\
£ 1.714 \mathrm{M})\end{array}$ & $\begin{array}{l}£ 1.548 \mathrm{M} \\
(£ 1.495 \mathrm{M}, \\
£ 1.600 \mathrm{M})\end{array}$ & $\begin{array}{l}£ 1.454 \mathrm{M} \\
(£ 1.412 \mathrm{M}, \\
£ 1.496 \mathrm{M})\end{array}$ \\
\hline
\end{tabular}




\begin{tabular}{|c|c|c|c|c|c|}
\hline $\begin{array}{c}\text { Total Cut on } \\
\text { Reimbursement } \\
\text { (Penalty) }\end{array}$ & $\begin{array}{c}£ 124,341 \\
(£ 112,623.2, \\
£ 136,058.9)\end{array}$ & $\begin{array}{l}£ 120,202.4 \\
(£ 106,570.3, \\
£ 133,927.5)\end{array}$ & $\begin{array}{l}£ 105,470.5 \\
(£ 96,540.2, \\
£ 114,642.8)\end{array}$ & $\begin{array}{c}£ 88,621 \\
(£ 78,834.5, \\
£ 98,775.4)\end{array}$ & $\begin{array}{c}£ 78,568 \\
(£ 70,069.8, \\
£ 87,660.2)\end{array}$ \\
\hline $\begin{array}{c}\text { Total Revenue of } \\
\text { Hospital }\end{array}$ & $\begin{array}{l}£ 4.083 \mathrm{M} \\
(£ 3.959 \mathrm{M}, \\
£ 4.208 \mathrm{M})\end{array}$ & $\begin{array}{l}£ 4.202 \mathrm{M} \\
(£ 4.054 \mathrm{M}, \\
£ 4.308 \mathrm{M})\end{array}$ & $\begin{array}{l}£ 4.142 \mathrm{M} \\
(£ 4.042 \mathrm{M}, \\
£ 4.201 \mathrm{M})\end{array}$ & $\begin{array}{l}£ 3.937 \mathrm{M} \\
(£ 3.834 \mathrm{M}, \\
£ 4.000 \mathrm{M})\end{array}$ & $\begin{array}{l}£ 3.896 \mathrm{M} \\
(£ 3.809 \mathrm{M}, \\
£ 3.943 \mathrm{M})\end{array}$ \\
\hline
\end{tabular}

QALY: Quality-adjusted life year. PR: Pulmonary Rehabilitation. M: Million. 
Table 7 Nurse, consultant, physiotherapist service hours and its associated costs over 3-year period.

\begin{tabular}{|c|c|c|c|c|c|c|}
\hline & Staff Type & Baseline & Worst & Pessimistic & Realistic & Optimistic \\
\hline \multirow{3}{*}{ 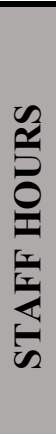 } & Nurse & $\begin{array}{l}39185 \\
(37916, \\
40455)\end{array}$ & $\begin{array}{l}38435 \\
(36959, \\
39911)\end{array}$ & $\begin{array}{l}38573 \\
(37091, \\
40032)\end{array}$ & $\begin{array}{l}35928 \\
(34876, \\
36980)\end{array}$ & $\begin{array}{l}33898 \\
(32874, \\
34923)\end{array}$ \\
\hline & Consultant & $\begin{array}{l}4600(4502, \\
4697)\end{array}$ & $\begin{array}{l}4474(4368 \\
4580)\end{array}$ & $\begin{array}{l}4481 \quad(4373, \\
4589)\end{array}$ & $\begin{array}{l}4252 \text { (4175, } \\
4330)\end{array}$ & $\begin{array}{l}4075 \text { (4006, } \\
4144)\end{array}$ \\
\hline & Physiotherapist & $\begin{array}{l}878 \quad(815, \\
942)\end{array}$ & $\begin{array}{l}1898(1773, \\
202)\end{array}$ & $\begin{array}{l}1918 \text { (1794, } \\
\text { 2041) }\end{array}$ & $\begin{array}{l}1859 \text { (1751, } \\
1967)\end{array}$ & $\begin{array}{l}1848(1734, \\
1961)\end{array}$ \\
\hline \multirow{3}{*}{ 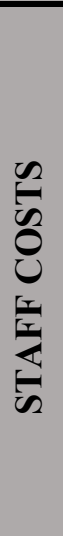 } & Nurse & $\begin{array}{l}£ 607,373 \\
(£ 587,693, \\
£ 627,052)\end{array}$ & $\begin{array}{l}£ 595,739 \\
(£ 572,856, \\
£ 618,622)\end{array}$ & $\begin{array}{l}£ 597,878 \\
(£ 574,913, \\
£ 620,497)\end{array}$ & $\begin{array}{l}£ 556,882 \\
(£ 540,576, \\
£ 573,189)\end{array}$ & $\begin{array}{l}£ 525,423 \\
(£ 509,547, \\
£ 541,299)\end{array}$ \\
\hline & Consultant & $\begin{array}{l}£ 275,957 \\
(£ 270,097, \\
£ 281,817)\end{array}$ & $\begin{array}{l}£ 268,445 \\
(£ 262,087, \\
£ 274,804)\end{array}$ & $\begin{array}{l}£ 268,833 \\
(£ 262,352, \\
£ 275,313)\end{array}$ & $\begin{array}{l}£ 255,106 \\
(£ 250,467, \\
£ 259,746)\end{array}$ & $\begin{array}{l}£ 244,499 \\
(£ 240,331, \\
£ 248,666)\end{array}$ \\
\hline & Physiotherapist & $\begin{array}{l}£ 16,917 \\
(£ 15,687, \\
£ 18,146)\end{array}$ & $\begin{array}{l}£ 36,554 \\
(£ 34,142, \\
£ 38,966)\end{array}$ & $\begin{array}{l}£ 36,932 \\
(£ 34,551, \\
£ 39,313)\end{array}$ & $\begin{array}{l}£ 35,794 \\
(£ 33,714, \\
£ 37,874)\end{array}$ & $\begin{array}{l}£ 35,582 \\
(£ 33,405, \\
£ 37,759)\end{array}$ \\
\hline
\end{tabular}


Figure 1. Conceptualised pathway for COPD patients. NIV: Non-Invasive Ventilation, PC: Primary Care, GP: General Practitioner, MAU: Medical Assessment Unit, ICU: Intensive Care Unit, CS: Community Services, A\&E: Accident and emergency.

Figure 2. Software Snapshot of the treatment process for COPD patients. NIV: Non-Invasive Ventilation, PC: Primary Care, GP: General Practitioner, MAU: Medical Assessment Unit, ICU: Intensive Care Unit, CS: Community Services, A\&E: Accident and emergency, FA: First Attendance, FUP: Follow-up, DNA: Did not Attend, HCA: Healthcare Assistant, MDT: Multidisciplinary Team, GOLD: Global Initiative for COPD.

Figure 3. Comparison of Inpatient Models (Left Hand Side) and Explanation of Readmission (Right Hand Side) - see text for details.

Figure 4. Graph for determining the warm-up period for number of patients assessed for PR. PR: Pulmonary Rehabilitation.

Figure 5. Simulation results of total cost and total QALY for each scenario (mean values 95\% CIs were omitted from the figure). 


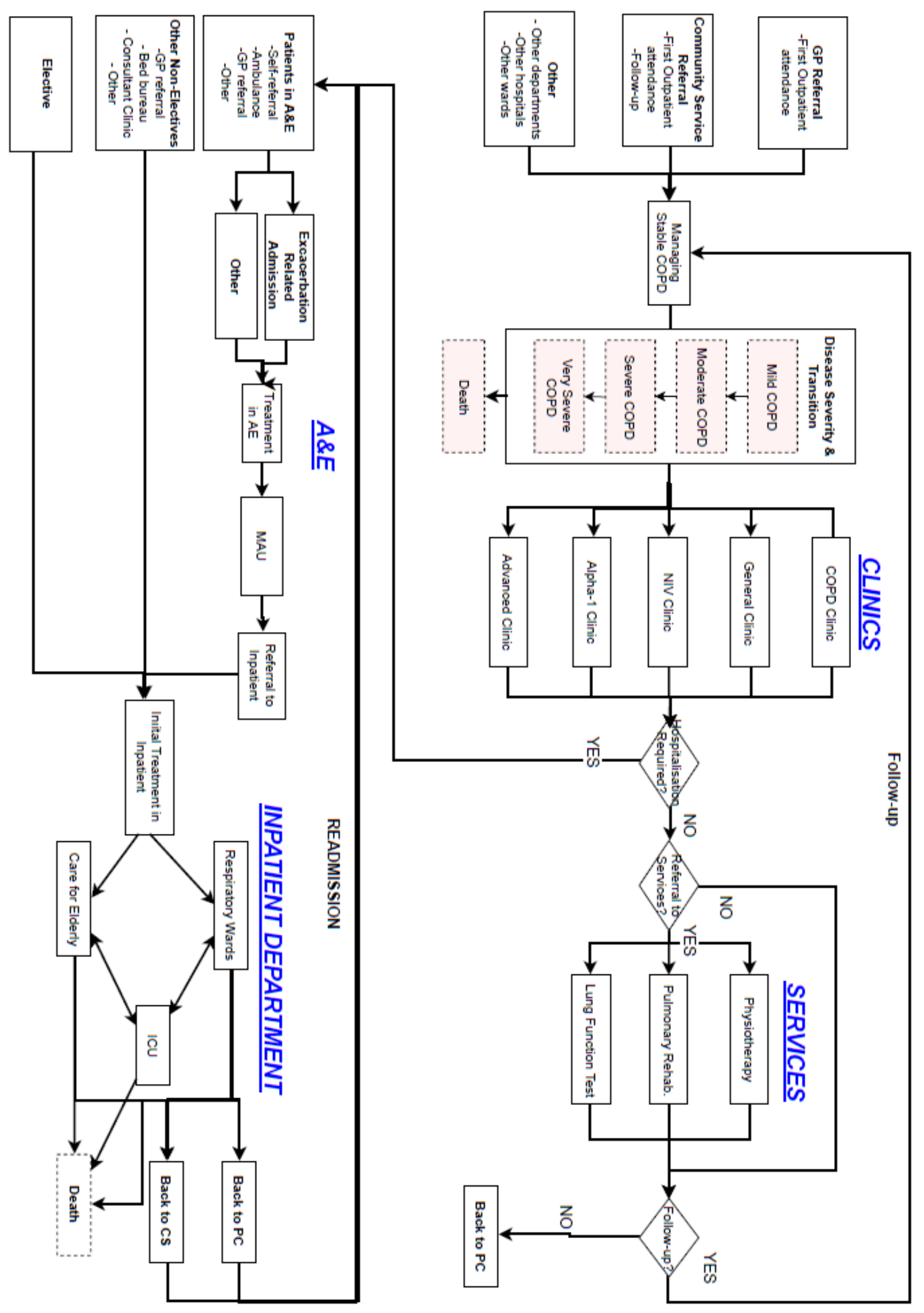

Figure 1 




Figure 2 




INPATIENT MODELLING with READMISSION

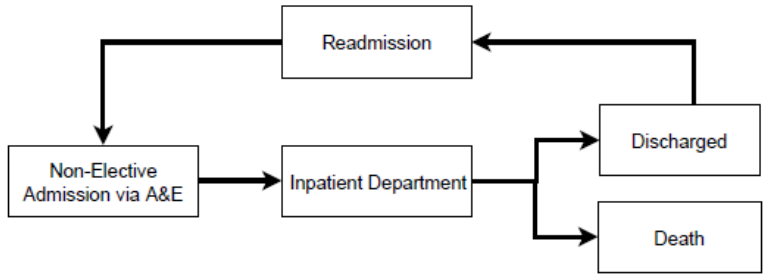

$\mid$

Figure 3 




Figure 4 


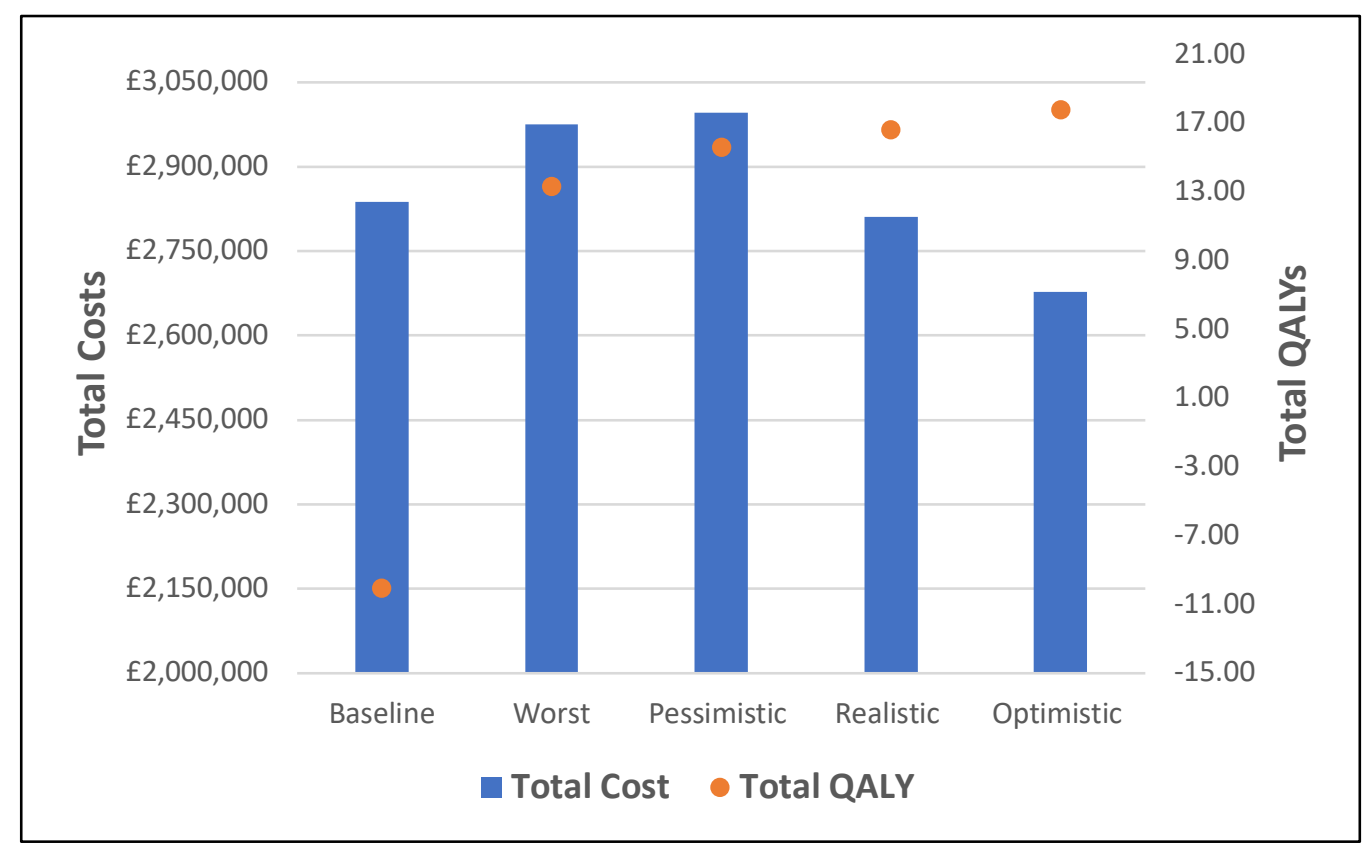

Figure 5 
